\title{
Effects of Countdown Signals in Red Phase on Drivers: A Comparative Study between Japan and Turkey
}

\author{
Ke Yu and Huapu Lu \\ Institute of Transportation Engineering, Tsinghua University, Beijing 100084, China \\ Correspondence should be addressed to Ke Yu; yukekeyu1982@163.com
}

Received 7 August 2014; Revised 15 November 2014; Accepted 19 November 2014; Published 30 December 2014

Academic Editor: Yingwei Zhang

Copyright (C) $2014 \mathrm{~K}$. Yu and H. Lu. This is an open access article distributed under the Creative Commons Attribution License, which permits unrestricted use, distribution, and reproduction in any medium, provided the original work is properly cited.

\begin{abstract}
Countdown signals can be found in many countries; however, there are only a few researches that study the impact of the signals on driver behavior. In this study, we focus particularly on the behavior of drivers reacting to countdown signals when the signal shifted from red to green. Although the countdown signal can reduce startup delay, it also causes drivers premature start. This paper determines the factors influencing the behaviors of drivers on startup delay, premature start, and headway due to countdown signals. The analysis results are compared between Japan and Turkey. From our findings, we propose countermeasures to reduce the problems caused by the countdown signals which can be a guideline for implementation or modification of countdown-signalized intersections in many countries in order to increase safety of both drivers and pedestrians as well as drivers' satisfactions.
\end{abstract}

\section{Introduction}

Countdown-signalized intersections, in which the remaining red or green times are displayed together with signal lights, have been widely applied to many countries such as China, Thailand, and Turkey. The countdown signal can be for drivers or for pedestrians. In Japan, the countdown signals for pedestrian are commonly found. This type of signal displays the waiting time or remaining time for pedestrians mainly for safety reasons. However, there are still very few researches on the analysis; in particular, the countdown signals for cars are still yet implemented in the country. In Japan, it is often said that the cycle length of traffic signal is relatively long comparing with that of the other countries such as European countries or the United States. In addition, there is no information on the remaining green time or red time provided to drivers. This causes drivers' difficulties to correctly estimate the time when the signal changes to red during the green light or vice versa. Also, during the red light, drivers may feel uncomfortable and feel waiting longer time for the green signal than the actual waiting time. This might cause mistake in decision for drivers due to stress.

A proper management of traffic signal can reduce drivers' stresses and mistakes. Countdown signal is considered as one of the best measures to reduce driving stress. With the countdown signals, drivers can estimate the proper timing for maneuvers at intersections, resulting in a smoother traffic stream and improved safety. However, there are only a few studies related to drivers' interaction with the countdown signals. An example is the work of Lum and Halim (2006) [1-9]. They set up a green signal countdown device (GSCD) and conducted a before-and-after study on the effects of the device (including before installation and after installation for 1.5, 4.5, and 7.5 months). The effects of the device are examined whether displaying the remaining green time can reduce the proportion of red light violation. Their findings demonstrated clearly an improvement after the installation of GSCD, especially when traffic volume is relatively high. However, there was no further analysis on the behaviors related to different setting of the device [10-13].

On the contrary, many researchers have conducted the effects of countdown signals for pedestrians. For example, Yoda and Mitsuboshi (2001) examined the impacts of a pedestrian's countdown device on the pedestrians' behaviors [14]. However, there is still no study on such impacts on drivers. Hamaoka et al. (2008) performed a simulation to examine the effects of countdown signals on drivers' behaviors whether to pass through or to stop at an intersection. However, there 


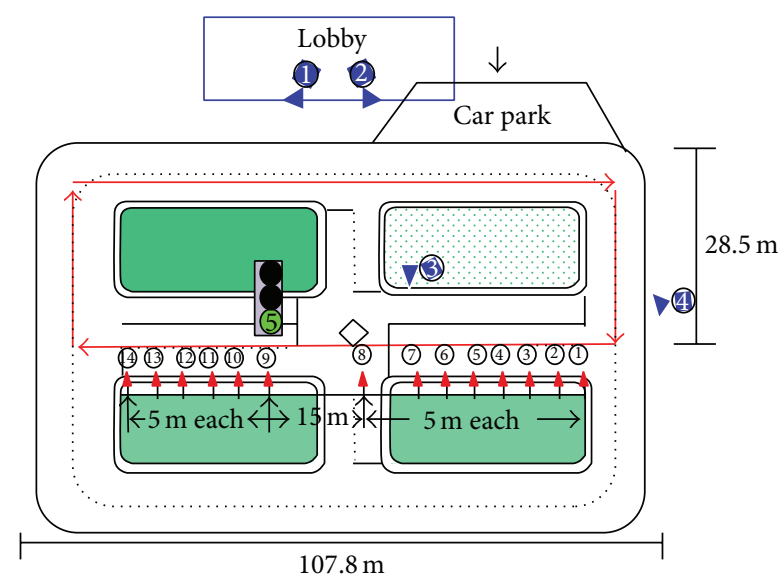

(a) Dec-2 experiment

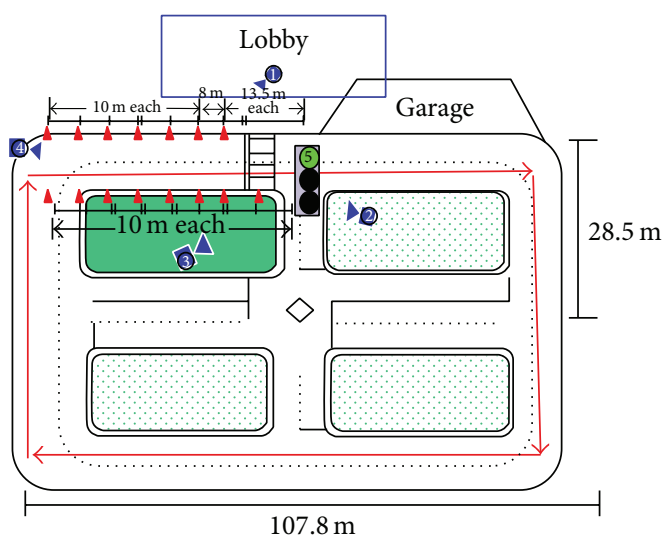

14 Camera

FIGURE 1: Layout of the device setting in the experiment.

is still yet experimented in reality. Fujita et al. (2007, 2008) have conducted surveys to compare drivers' behavior with and without countdown signals at two intersections in Turkey during the period from 2004 to 2005 [15-18]. They analyzed the behaviors of drivers to pass through, to stop, or to start when signals changed. However, the survey was conducted at only one intersection for each case and there might be many other factors influencing the results. Their findings suggest that countdown signal can increase the proportion of premature starts. However, there is still yet the analysis of drivers' behaviors related to their attributions.

In this study, we thus examine the behavior of drivers reacting when the signal switched from red to green lights at countdown signals. This paper focuses particularly on the problems of drivers on startup delay and premature start which occurred with and without the countdown signal. In many countries where the countdown devices are implemented, it is common that the countdown numbers are displayed until right before the signal actually changes. We consider it as an important factor causing drivers' premature start [19-25]. In this study, we thus analyze the drivers' responses to different settings of countdown (the remaining time) displayed on the signal in order to find the countermeasures for premature starts. In addition, a comparative study is presented based on an experiment at a test driving course in Japan and a field survey in Turkey where the countdown signals have been actually implemented. Analysis results of an experiment at a test driving course in Japan are compared with the results from a survey in Turkey. The data from the total of nine intersections (in both Japan and Turkey) is analyzed to observe drivers' maneuvers when signal changes from red to green. The experiment in Japan has an aim of comparing drivers' behaviors change due to various methods to display countdown number. In Turkey, as the countdown device has already been implemented, we also survey the impacts from pedestrians as well as from vehicles from other directions. Several impacts on drivers' behaviors due to countdown signals are analyzed from many perspectives and a number of models are developed to analyze the factors influence on drivers' startup delays and premature starts in both countries.

\section{Experiment at a Driving Course in Japan}

In this experiment, countdown signals are set up at a test driving course to study the drivers' behaviors due to different methods to display countdown number on the device. At the same time, a questionnaire survey was conducted to obtain drivers perspectives on the system.

2.1. Outline of Experiment. Two experiments were performed on December 2 and 9, 2007 (which are called Dec-2 and Dec9 experiments hereafter) at a driving course in Katsukai driving school, Aichi prefecture. We installed our own developed countdown-signal device at the driving course and requested 20 drivers to drive rental cars at the course. The drivers' maneuvers were recorded by video camera. The layouts of device setting in the Dec- 2 and Dec-9 experiments are presented in Figures 1(a) and 1(b), respectively. On both days, we tested different driving routes and different locations of the devices in order to assess the characteristics of countdown device as much as possible. The maximum distance for drivers to notice the signals is different between the experiments in order to consider the different impacts from driving speed and route distance. The route distances are $55 \mathrm{~m}$ and $80 \mathrm{~m}$ for Dec-2 and Dec-9 experiments, respectively.

The details on each of the experiments are as shown in Table 1. In order to obtain many parameters for the analysis, various methods to display countdown number in green and red lights were implemented. In the Dec-2 experiment, there were 7 driving routes from A to G. Six drivers were assigned to drive each route and are divided into 2 groups (1st and 2 nd rounds) so that 3 drivers can drive at a time. The experiment was performed in both morning and afternoon. The total driving routes are 14 patterns. In the Dec- 9 experiment, 6 patterns of driving routes from $\mathrm{A}$ to $\mathrm{F}$ were performed. 
TABLE 1: Countdown setting and signal cycle in the experiments.

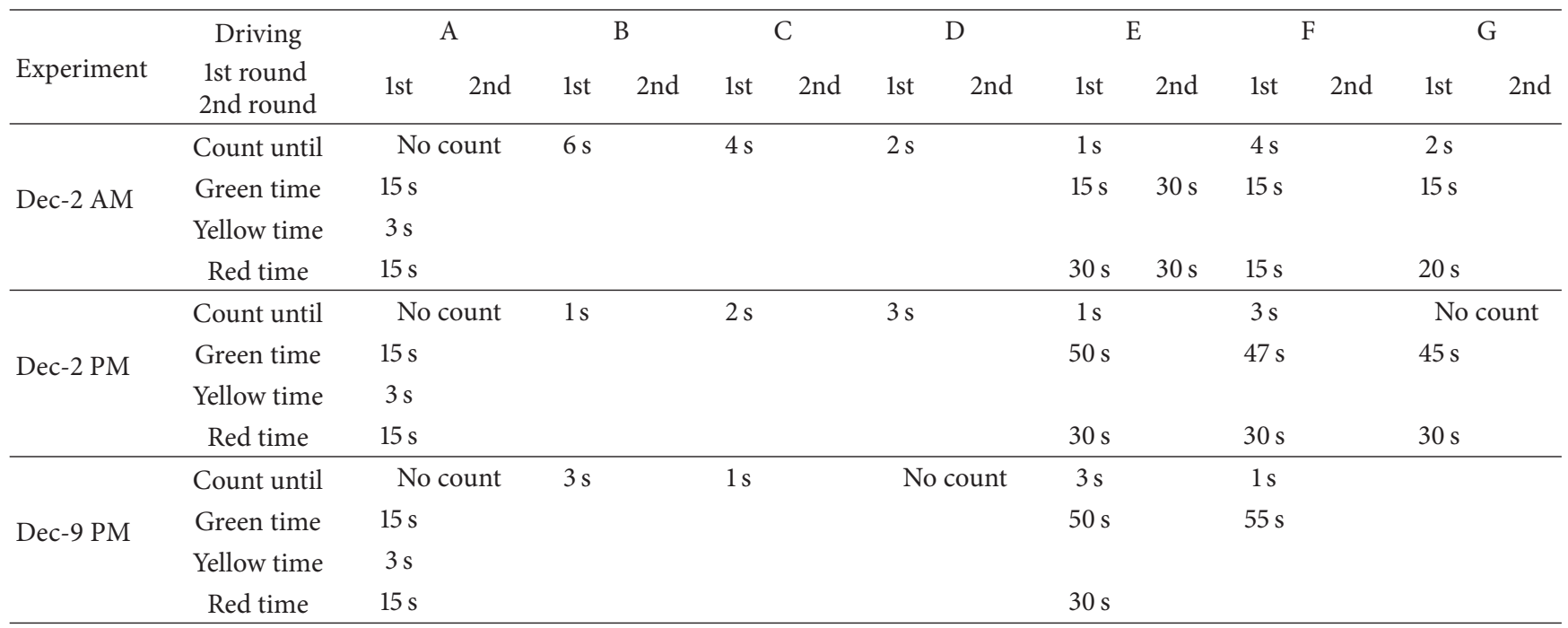

TABLE 2: Countdown display method.

Remaining red
time

Similarly, number of drivers and group division are the same as those done in the Dec-2 experiment, but we performed only in the afternoon. Finally, we obtained in total 20 patterns of driving routes for both days. At each time, there were 3 cars that drove the course of approximately 10 minutes in which the signals were set to be as similar to ones in the reality as possible. However, we still yet include parameters of driving status such as "in hurry driving" in this experiment.

Table 1 shows that the countdown device was set to display number in different ways. Originally, the device itself can display the countdown number until 1 second before the signal changes; however, in this study, we aim to observe the differences from various display methods. Therefore, the countdown numbers were set to display and stop at 6 seconds, 4 seconds, 2 seconds, and 1 second, respectively. However, in many countries where the countdown signals have already been implemented, it seems to be common that the countdown number is set to be displayed until a second before the signal changed. However, in previous studies, we found that drivers tend to perform premature start at the countdown-signalized intersections. Therefore, in this study, we will test our assumption that to stop displaying the countdown numbers earlier can reduce the problem of premature start. For example, "count until 6 seconds" means the device displays countdown number of the remaining green or red time and stops at number 6 and, for the remaining 5 seconds, it displays only green or red light with no number until the signal changes. For better understanding, Table 2 shows the display method of countdown signals for each case.

Every time after finishing driving, each driver was asked to fill questionnaires about their satisfactions on the system. The questions include (1) comfortable driving, (2) safety, (3) stopping satisfaction, (4) starting satisfaction, and (5) passing satisfaction. In addition to these questions, after all 
TABLE 3: Drivers and their attributes.

\begin{tabular}{lcc}
\hline \multicolumn{2}{c}{ Attributes } & Number of drivers \\
\hline \multirow{2}{*}{ Sex } & Male & 16 \\
& Female & 4 \\
\hline \multirow{3}{*}{ Age } & $20-29$ & 15 \\
& $40-49$ & 1 \\
& $50-59$ & 2 \\
Driving experience & $60-69$ & 1 \\
& $70-79$ & 1 \\
\hline \multirow{3}{*}{ Driving frequency } & Less than 10 years & 14 \\
& More than 30 years & 3 \\
& Every day & 3 \\
\hline & Once a week & 7 \\
& Less than twice a month & 8 \\
\end{tabular}

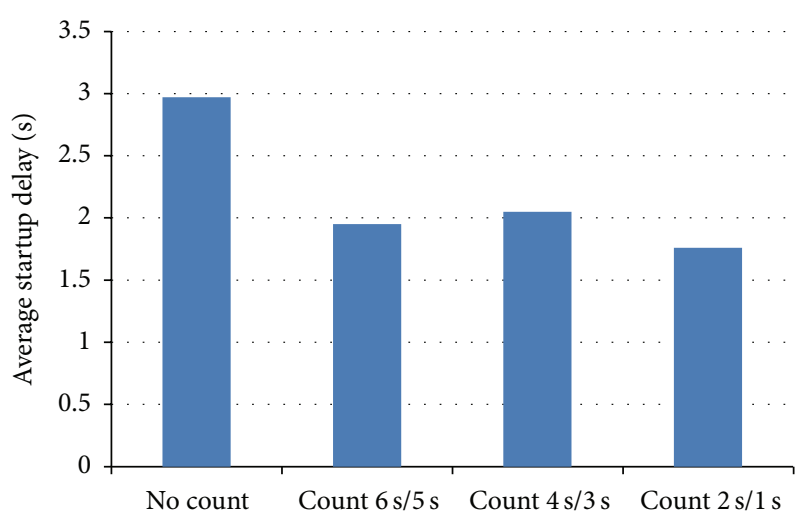

Figure 2: Average start delay in relation with countdown methods.

the experiments finished, drivers were asked to choose the best setting among all the countdown methods. Drivers' attributes, including sex, age, driving experience, and driving frequency, were also included in the questionnaires. Table 3 summarizes the attribution of drivers in the experiments.

2.2. Analysis of Startup Delay, Premature Start, and Headway. In this section, we analyze the behavior of drivers on startup delay and premature start of the first vehicles and on headway of the second and third vehicles in the queue.

(1) Behavior of the First Vehicle in the Queue. Using the records from video camera, drivers' maneuvers at the intersections were observed and used for analysis of the factors causing startup delay and premature start. Startup delay and premature start are defined as follows.

Startup delay time: it is time difference between the time when signal changes from red to green and the time when the head of vehicle actually passes the stop line.

Premature start: it is when a vehicle waiting at a signal moves across the stop line before the signal actually changes from red to green. Figure 2 shows the average start delays in relation with countdown methods. Here, for example, Count $6 \mathrm{~s} / 5 \mathrm{~s}$ means the remaining red time is counted down until 6

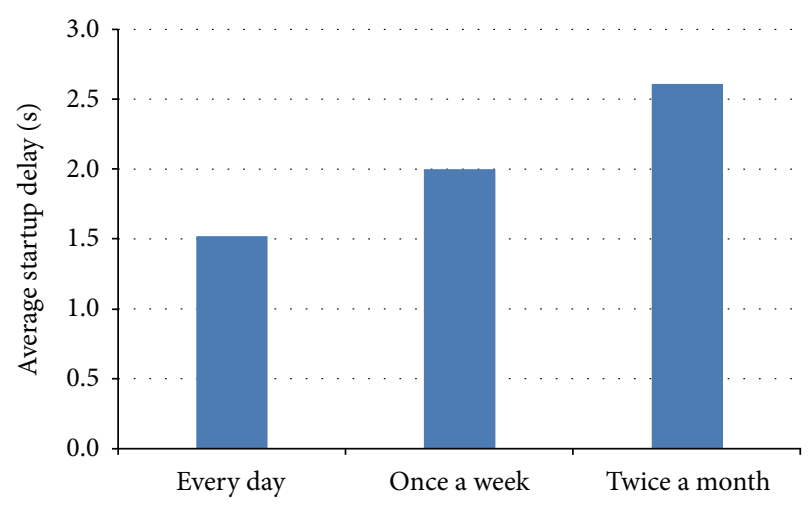

FIGURE 3: Average start delay in relation with driving frequency.

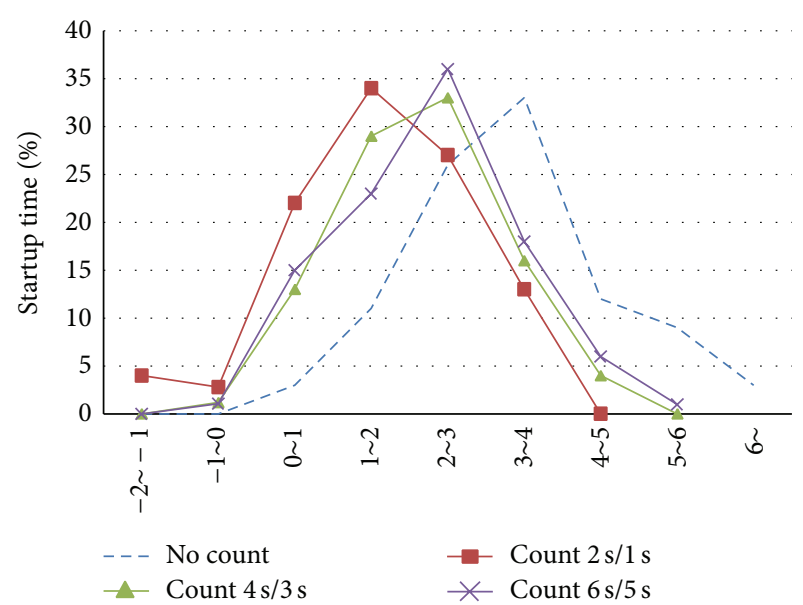

FIGURE 4: Distributions of startup time by types of display method.

seconds and the signal displays the light with no number for the remaining 5 seconds. Similarly, Count $4 \mathrm{~s} / 3 \mathrm{~s}$ and Count $2 \mathrm{~s} / 1 \mathrm{~s}$ mean displaying numbers until 4 seconds and show no number for the remaining 3 seconds and displaying numbers until 2 seconds and show no number for the remaining 1 second before the signal changes, respectively. Comparing between displaying countdown numbers and no countdown, the results show that countdown signal can reduce the average startup delay by approximately a second. However, there is no distinguished difference among the results for different display methods. Figure 3 shows the relationship between the average start delay and driving frequency. Drivers who normally drive less frequently tend to have the longer startup delays.

2.2.1. Startup Delay. Figure 4 depicts the distributions of startup delay by types of display method. The results show that countdown signals of $6 \mathrm{~s} / 5 \mathrm{~s}, 4 \mathrm{~s} / 3 \mathrm{~s}$, and $2 \mathrm{~s} / 1 \mathrm{~s}$ can reduce more startup delay, respectively. The countdown signal can reduce startup delay; however, at the same time, premature starts occurred in all cases that display the countdown numbers and were particularly high for Count $2 \mathrm{~s} / 1 \mathrm{~s}$. While there was no premature start occurring at all in case of no 
count, the extreme case of startup delay by 6 seconds also occurred.

A regression model is developed in order to obtain the factors influencing startup delay. The parameters included in the model are countdown method, waiting time at the intersection, distance from stop line, driving experience, and driving frequency. Table 5 shows the results from calibration.

For driving frequency, we set driving every day $=3$, once a week $=2$, and twice a month $=1$ in the model. The model has a rather high $R$ and statistically represents the data. Considering the results, the lower negative of the parameter means the shorter value of the startup delay. All parameters of Count $6 \mathrm{~s} / 5 \mathrm{~s}$, Count $4 \mathrm{~s} / 3 \mathrm{~s}$, and Count $2 \mathrm{~s} / 1 \mathrm{~s}$ have negative values, which mean that countdown signal can reduce startup delay. This proves that countdown signal can make it easy for drivers to estimate the proper timing to start maneuver, resulting in better discharges of traffic flow. For other parameters, the farther the distance of the head of vehicle to the stop line, the longer the start delay. Drivers having longer driving experience and higher driving frequency tend to have smaller start delay. This is because the drivers know better driving technique and can predict the better timing to start maneuver.

2.2.2. Premature Start. In the same way, we analyze the driver behavior on premature start. The premature start is defined as when a vehicle waiting at a signal moves across the stop line before the signal actually changes from red to green. Here, we set the vehicle with premature start to 1 and otherwise to 0 as the dependent variable in order to analyze the behavior using a logistic regression. The parameters input into the model include countdown method, waiting time at the intersection, distance from stop line, driving experience, and driving frequency. The calibration results of the logistic regression model are depicted in Table 5. The parameters waiting time, driving frequency, and Count $2 \mathrm{~s} / 1 \mathrm{~s}$ are positives, while the parameters no count, Count $6 \mathrm{~s} / 5 \mathrm{~s}$, distance from stop line, and driving experience are negatives. The results demonstrate that the longer the waiting time, the higher the driving frequency, and to display the countdown number until small number can induce drivers' premature starts. On the other hand, if there is no countdown number displayed, vehicles are far from the stop line, or driver has a long driving experience, the problem of premature starts can be lessened.

Considering $t$-values of parameters distance from stop line and waiting time are rather relevant to premature start. The longer waiting time can lead to premature start as drivers were longing for the green light. Comparing the results together, Table 4 suggests countdown displayed as the key to reduce startup delay; but the results in Table 5 show that it also leads to the possibility of premature start.

In order to control the premature starts, it is perhaps better not to show the countdown numbers at all. However, due to many reasons for which the countdown signal is preferred (such as to reduce startup delay and driver stress and for safety reasons), we suggest better to stop displaying the number a little while before and remain the light with no count until the signal changes. This method leaves the exact
TABLE 4: Startup delay model.

\begin{tabular}{lcc}
\hline Parameters & Coefficients & $t$-value \\
\hline Intercept & 2.51 & 7.37 \\
Count $6 \mathrm{~s} / 5 \mathrm{~s}$ & -0.43 & -3.72 \\
Count $4 \mathrm{~s} / 3 \mathrm{~s}$ & -0.55 & -3.93 \\
Count $2 \mathrm{~s} / \mathrm{s} \mathrm{s}$ & -0.71 & -4.46 \\
Waiting time (second) & -0.31 & -2.29 \\
Distance from stop line (meters) & 0.74 & 2.57 \\
Driving experience (years) & -0.23 & -2.19 \\
Driving frequency & & \\
(every day = 3, once a week $=2$, & -0.62 & -4.02 \\
twice a month = 1) & & \\
$R$ & \multicolumn{2}{c}{0.71} \\
Number of samples & \multicolumn{2}{c}{419} \\
\hline
\end{tabular}

TABle 5: Premature start model.

\begin{tabular}{lcc}
\hline Parameters & Coefficients & $t$-value \\
\hline Intercept & 2.07 & 4.58 \\
Count $6 \mathrm{~s} / 5 \mathrm{~s}$ & 0.72 & 3.39 \\
Count $4 \mathrm{~s} / 3 \mathrm{~s}$ & -0.51 & -3.42 \\
Count $2 \mathrm{~s} / \mathrm{s}$ & -1.09 & -2.30 \\
Waiting time (second) & -0.92 & -2.53 \\
Distance from stop line (meters) & 0.33 & 2.95 \\
Driving experience (years) & -1.35 & -1.86 \\
Driving frequency & \multicolumn{2}{c}{} \\
(every day =3, once a week $=2$, & 1.28 & 2.01 \\
twice a month = 1) & \multicolumn{2}{c}{0.30} \\
$\rho^{2}$ & \multicolumn{2}{c}{90.23} \\
Hit ratio & \multicolumn{2}{c}{419} \\
Number of samples & \multicolumn{2}{c}{} \\
\hline
\end{tabular}

timing of signal change unclear to drivers but drivers still were alerted by the countdown number previously.

(2) Behavior of the Second and Third Vehicles in the Queue. In order to assess to the impacts on other vehicles in the same queue, we analyze the time headway in order to obtain the impacts of countdown device on the second and third vehicles in the queue. Obviously, the shorter headway is preferable, especially in dense urban cities as it is considered as one of the factors to alleviate traffic congestion. In this study, the headway is defined as the time required for the vehicle $([n+1]$ th vehicle) in the queue moving past the stop line after its front vehicle ( $n$th vehicle) has passed.

Figure 5 depicts the distribution of headway of the second and third vehicles in the queue by types of display method. The result shows that there is no clear difference among the values for no count, Count $4 \mathrm{~s} / 3 \mathrm{~s}$, and Count $2 \mathrm{~s} / 1 \mathrm{~s}$. However, Count $6 \mathrm{~s} / 5 \mathrm{~s}$ has shown a better improvement on headway reduction. From the previous analyses, Count $6 \mathrm{~s} / 5 \mathrm{~s}$ can reduce a smaller amount of startup delay comparing with other countdown methods. As the countdown number disappeared in the middle, drivers of the next vehicles receive 


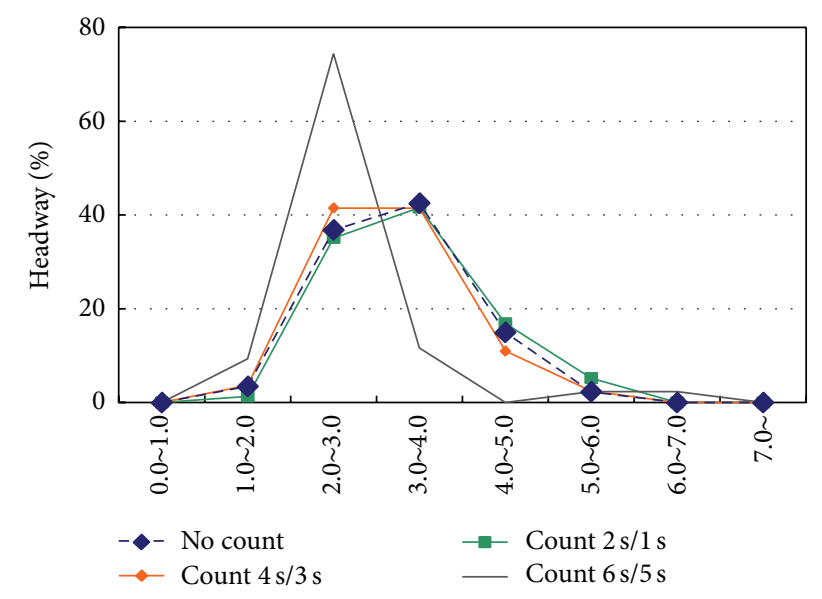

Figure 5: Distribution of headway of the next vehicles in the queue by types of display method.

the information that it is almost the green time so that the drivers start early to prepare for maneuver. This results in the shorter distance between the cars and consequences in the shorter time headway.

We also developed a model to analyze the factors influence on the headway of the second and third vehicles in the queue. The results are as shown in Table 6 . The parameters included in the model are countdown method, driving experience, driving frequency, and the vehicle rank in the queue. The parameters for Count $4 \mathrm{~s} / 3 \mathrm{~s}$, Count $2 \mathrm{~s} / 1 \mathrm{~s}$, and no count are positive, which mean that these are factors to increase the time headway. From the previous analyses, Count $4 \mathrm{~s} / 3 \mathrm{~s}$ and Count $2 \mathrm{~s} / 1 \mathrm{~s}$ can reduce a significant amount of startup delay of the first vehicle and, at the same time, cause premature start of the vehicle. Therefore, this increases the time gap between the first and the next vehicles in the queue. On the contrary, the parameter for Count $6 \mathrm{~s} / 5 \mathrm{~s}$ is negative and can be interpreted as factor to reduce the headway as from the reasons stated above. For driver attributes, drivers with more experience and driving more frequently can better shorten the headway.

\section{A Survey on Countdown Signals in Turkey}

In Turkey, as the countdown signals have already been installed on the real roads, we conducted a field survey using video cameras to record the vehicles' maneuvers at intersections (both with and without the countdown signals). The survey was conducted at intersections in Kayseri Province during the period from September 15 to 18, 2009. The details of survey are as shown in Table 7 (intersections' names are abbreviated in parentheses).

The survey was conducted in a total of 9 directions at 7 intersections. Table 8 shows the detailed information of each intersection. In the table, the number of lanes means the number for one direction which indicates number of lanes in the observed direction. In Kayseri province, CCTV cameras are sometimes installed together with countdown signals. Drivers can notice whether there is a CCTV camera
TABLE 6: Model for headway of the second and third vehicles.

\begin{tabular}{lcc}
\hline Parameters & Coefficients & $t$-value \\
\hline Intercept & 3.87 & 9.52 \\
Rank in the queue & -0.51 & -1.99 \\
Count $6 \mathrm{~s} / 5 \mathrm{~s}$ & -0.27 & -4.11 \\
Count $4 \mathrm{~s} / 3 \mathrm{~s}$ & 0.41 & 3.58 \\
Count $2 \mathrm{~s} / 1 \mathrm{~s}$ & 0.19 & 3.02 \\
No count & 0.32 & 2.43 \\
Driving experience & -0.19 & -2.01 \\
Driving frequency & & \\
(every day = 3, once a week $=2$, & -0.52 & -3.77 \\
twice a month =1) & \multicolumn{2}{c}{0.69} \\
$R$ & \multicolumn{2}{c}{288} \\
Number of samples & \multicolumn{2}{c}{} \\
\hline
\end{tabular}

TABLE 7

September 9, 2009

7:00-10:15 Fuzuli Southbound (Fuz)

Fuzuli Northbound $(\mathrm{F}(\mathrm{C}))$, with countdown signal

16:00-18:00 Hastane39 (H39)

\begin{tabular}{lc}
\hline $\begin{array}{l}\text { September 16, 2009 } \\
\text { 16:00-18:00 }\end{array}$ & Sanayi (San) \\
\hline $\begin{array}{l}\text { September 17, 2009 } \\
\text { 8:00-10:00 }\end{array}$ & $\begin{array}{c}\text { Ceveryol5 (Cev5), with countdown signal } \\
\text { Ceveryol6 Westbound (C6W), with } \\
\text { countdown signal }\end{array}$ \\
$\begin{array}{l}\text { 16:00-18:00 } \\
\text { September 18, 2009 } \\
\text { 8:30-9:30, 13:00-14:00 }\end{array}$ & $\begin{array}{c}\text { Argincik (Arg) } \\
\text { 10:15-12:15 }\end{array}$ \\
\hline
\end{tabular}

or not from a traffic sign board. Different to Japan, in Turkey, the signal cycle displays yellow light when the signal turns both from red to green and from green to red. The countdown signal also shows the countdown of yellow time. However, the analyses of premature start and startup delay are performed considering the total time required until green light is displayed. There might be some differences because of the different systems of the two countries as, in Japan, traffic signals change from red and to green without yellow light in between. In order to be able to compare, we consider the total time until the signal changes to green for analyses of both countries. The intersections are also categorized by locations: urban and other.

3.1. Startup Delay and Premature Start due to Countdown Signal in Turkey. The definitions of premature start and startup delay are the same as ones used in the analysis for the Japan experiment. In addition, there is no stop line at some intersections in Turkey. Therefore, we use the real stop line when available, otherwise, assuming the position of signal 
TABLE 8: Detailed information of survey at each intersection.

\begin{tabular}{lccccccccccc}
\hline Intersection & Direction & $\begin{array}{c}\text { Number of } \\
\text { lanes in } \\
\text { direction } \\
\text { of interest }\end{array}$ & $\begin{array}{c}\text { Number of } \\
\text { lanes in } \\
\text { the } \\
\text { opposite } \\
\text { direction }\end{array}$ & $\begin{array}{c}\text { Proportion } \\
\text { of large } \\
\text { vehicles }\end{array}$ & $\begin{array}{c}\text { With } \\
\text { count- } \\
\text { down } \\
\text { device }\end{array}$ & CCTV & $\begin{array}{c}\text { Cycle } \\
\text { time (s) }\end{array}$ & $\begin{array}{c}\text { Green } \\
\text { time (s) }\end{array}$ & $\begin{array}{c}\text { Yellow } \\
\text { time (s) }\end{array}$ & $\begin{array}{c}\text { Number } \\
\text { of } \\
\text { aspects }\end{array}$ & Urban \\
H39 & East & 2 & 2 & 6 & No & No & 80 & 36 & 3 & 4 & 1 \\
H101 & Northeast & 2 & 2 & 27 & Yes & No & 80 & 31 & 3 & 6 \\
Fuz & Southeast & 2 & 2 & 11 & No & No & 69 & 16 & 2 & 4 \\
Arg & Northwest & 3 & 3 & 13 & No & No & 100 & 26 & 2 & 3 \\
Cev5 & Westbound & 3 & 3 & 11 & Yes & No & 100 & 34 & 3 & 5 \\
C6W & Westbound & 3 & 3 & 19 & Yes & Yes & 100 & 34 & 2 & 4 \\
C6S & Northbound & 3 & 3 & 15 & Yes & Yes & 100 & 28 & 3 & 4 \\
San & Westbound & 3 & 3 & 7 & No & No & 100 & 34 & 3 & 6 \\
F(C) & Northwest & 2 & 2 & 9 & Yes & No & 69 & 15 & 2 \\
\hline
\end{tabular}

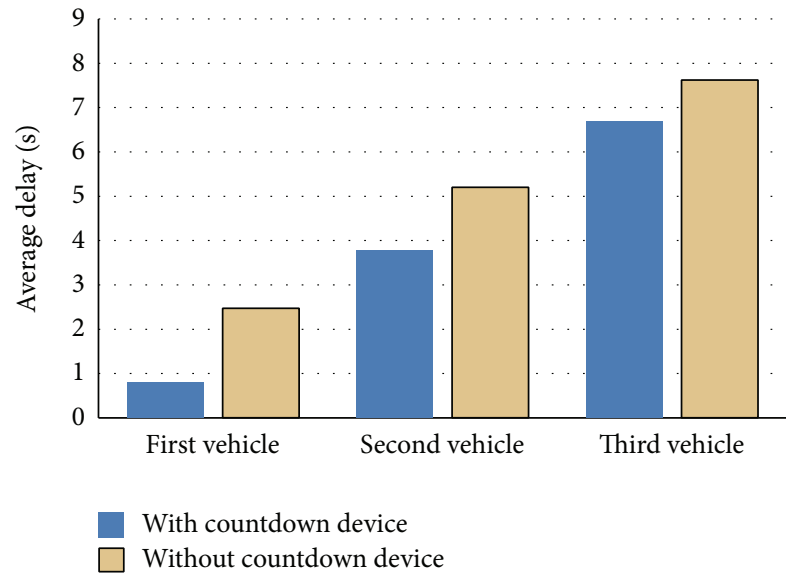

Figure 6: Startup delay with and without countdown devices.

as the stop line for analysis. In this section, we also analyze the third vehicle passing time, which is defined as the time difference between the time when signal turns from red to green and the time when the third vehicle actually passes the stop line. Figure 6 depicts the startup delay comparing cases with and without countdown devices for the first until the third vehicle. The results prove that countdown signal can decrease startup delay from the first until the third vehicle.

Figure 7 compares the distributions of startup time of all intersections both with and without countdown signal. In the graph, the installation of countdown signal is indicated by a solid line and otherwise by a dashed line. CCTV indicates the installation of CCTV camera. From the results, the intersections with no countdown signal generate not at all the premature start but, at the same time, they caused very large startup delays of more than 5 seconds. On the other hand, intersections with countdown signals significantly shortened startup delay; however, at the same time, the premature start occurred. Focusing at intersections C6W and C6S, no premature start occurred because both the countdown signals and CCTV are installed at the intersections. This indicates that installation of CCTV together with strong regulation

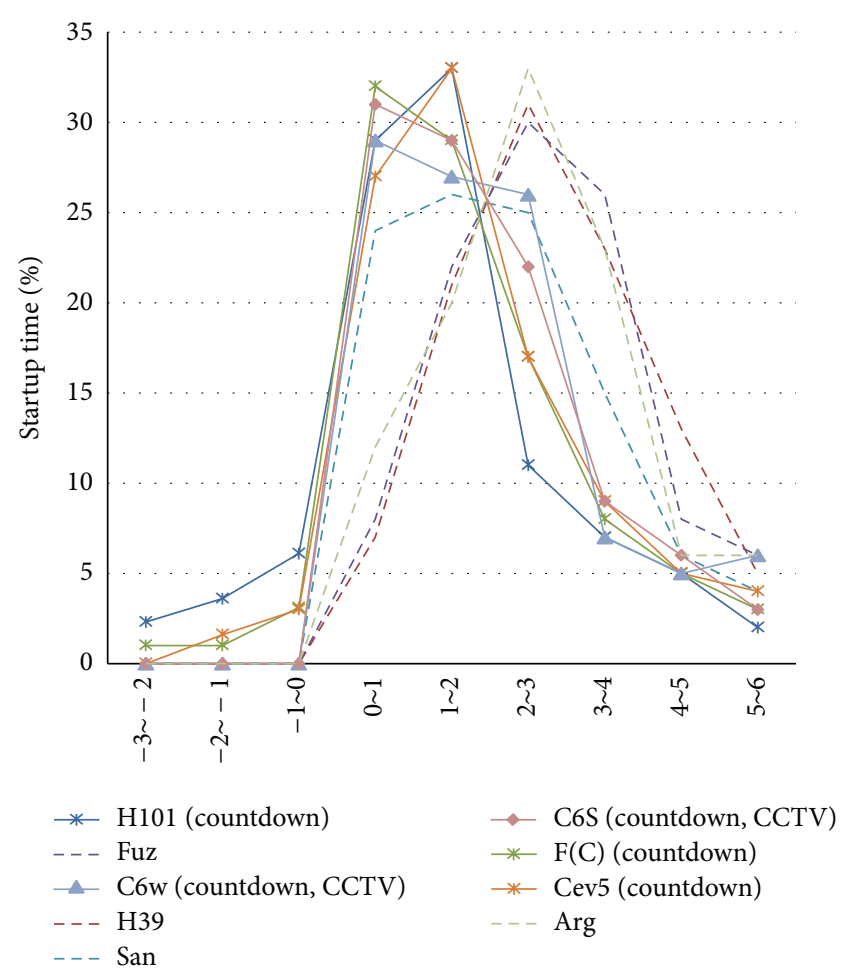

Figure 7: Distribution of startup time at intersections in Turkey.

(such as a fine to vehicle which undergoes the red light) can prevent problem of premature start. Behavioral models on premature start and startup delay for Turkey are constructed using parameters similar to ones used for Japan's models. Turkey's model can include more factors, such as pedestrian and number of vehicles remaining in the queue, because the countdown signals are actually implemented. In addition, the impacts on small and large vehicles might be different; therefore, the dummies for vehicle types are also included in the model.

We developed models of three categories: Model 1: startup delay of the first vehicle, Model 2: time for the third vehicle 
passing stop line, and Model 3: premature start of the first vehicle. Models 1 and 2 are developed using regression technique to estimate the time durations. On the other hand, Model 3 is constructed using logistic regression to determine whether or not the vehicle performs premature start. The results are summarized in Table 9. The values of $R$ are approximately 0.8 for Models 1 and 2, while $\rho$ for Model 3 is more than 0.5 . All models are statistically significant.

Considering the negative signs of parameters large vehicle-w/CS, small vehicle-w/CS, and waiting time in Model 1 , startup delay can be shortened by these factors. Conversely, positive signs of parameters pedestrian, large vehicle-w/o CS, CCTV, Urban, and distance to stop line indicate that these factors cause the longer startup delay. In particular, the parameter large vehicle-w/o CS has the highest value and can be interpreted without countdown signal; large vehicle tends to make a very long startup delay. Installation of countdown signal can reduce this loss. In addition, CCTV and fine on violation cause drivers to be more cautious.

The startup delay tends to be longer for intersections in urban area. The reasons are, for example, that there are always pedestrians on the crosswalk and/or on the road side and roads in urban area mostly have two lanes and the lane width is rather narrow which force drivers to drive slower. The startup time becomes longer too if there is a straight or left-turning vehicle from other directions blocking the traffic (Turkey drives on the right side).

Next, Model 2 is for estimation of time required for the third vehicle to pass the stop line. In this model, the signs of parameters are similar to ones in Model 1 and can be interpreted similarly. Even though the estimated value of small vehicle-w/CS in Model 2 becomes smaller, the impact on large vehicles still unchanged. This demonstrates a positive effect of the countdown signal to reduce startup delay and even until the third vehicle, especially to large vehicles.

In Model 3, parameters Urban, large vehicle-w/CS, small vehicle-w/CS, and waiting time tend to be factors to provoke premature start. On the other hand, parameters distance to stop line, pedestrian, and large vehicle-w/o CS are factors to reduce premature start.

From Figure 7, premature starts occurred at intersections "H101," "Fuz" and "Cev5" where countdown signals are installed with no CCTV and the proportion of premature start is approximately 5-10 percent of all the vehicles, while, there is no premature start at intersections C6W and C6S where CCTVs were installed together with the countdown signals.

Similar to Japan's experiment, if there is countdown signal, the proportion of premature start becomes rather high in both countries. However, the other factors such as CCTV, pedestrian, distance from stop line, and waiting time tend to reduce premature start. In particular, CCTV performs an important role in alleviating this problem.

\section{Comparisons between Japan and Turkey}

4.1. Startup Delay. The average startup times for each case in both countries are compared in Table 10. In Japan's
TABLE 9: Startup delay and premature start models for Turkey.

\begin{tabular}{lccc}
\hline Parameters & Model 1 & Model 2 & Model 3 \\
\hline $\begin{array}{l}\text { Intercept } \\
\text { Waiting time }\end{array}$ & $2.34(4.89)$ & $2.27(4.03)$ & $2.39(7.24)$ \\
(sec) & $-0.27(-2.25)$ & $-0.36(-2.11)$ & $0.87(2.69)$ \\
$\begin{array}{l}\text { Distance from } \\
\text { stop line (m) }\end{array}$ & $0.33(2.83)$ & $0.29(2.07)$ & $-0.97(-2.82)$ \\
$\begin{array}{l}\text { Large } \\
\text { vehicle-w/CS }\end{array}$ & $-0.57(-2.17)$ & $-0.53(-2.30)$ & $1.01(3.47)$ \\
$\begin{array}{l}\text { Small } \\
\text { vehicle-w/CS }\end{array}$ & $-1.35(-3.72)$ & $-0.91(-3.06)$ & $1.63(4.21)$ \\
$\begin{array}{l}\text { Large } \\
\text { vehicle-w/o CS }\end{array}$ & $0.44(2.31)$ & $0.47(2.77)$ & $-0.96(-2.75)$ \\
$\begin{array}{l}\text { Pedestrian } \\
\text { Obstruction- } \\
\text { straight }\end{array}$ & $0.23(1.91)$ & $0.41(2.13)$ & $-0.77(-2.91)$ \\
vehicle & $0.25(2.10)$ & $0.31(2.45)$ & $-0.84(-1.91)$ \\
$\begin{array}{l}\text { Obstruction- } \\
\text { straight }\end{array}$ & $0.56(2.17)$ & $0.31(2.09)$ & $-0.91(-1.95)$ \\
vehicle & & & $-0.78(-3.73)$ \\
CCTV & $0.20(2.04)$ & $0.30(2.72)$ & $0.81(2.61)$ \\
Urban & $0.47(2.53)$ & $0.37(2.26)$ & 1627 \\
$R$ & 0.82 & 0.79 & 0.57 \\
$\begin{array}{l}\text { Number of } \\
\text { samples }\end{array}$ & 1627 & 1015 & 91.27 \\
$\rho$ & & & \\
Hit ratio & & & \\
\hline
\end{tabular}

Note. Model 1: startup delay of the first vehicle; Model 2: time for the third vehicle passing stop line; Model 3: premature start of the first vehicle.

experiment, there are different countdown display methods: count until 6 seconds (Count $6 \mathrm{~s} / 5 \mathrm{~s}$ ), count until 4 seconds (Count $4 \mathrm{~s} / 3 \mathrm{~s}$ ), and count until 2 seconds (Count $2 \mathrm{~s} / 1 \mathrm{~s}$ ), while, in Turkey, there is only one method for countdown, which is counting until 1 second before the signal changes. This is equivalent to the Japan's Count $1 \mathrm{~s} / 2 \mathrm{~s}$. The differences also include only light vehicles performed in Japan's experiment. Therefore, we will compare only between Japan's Count $2 \mathrm{~s} / 1 \mathrm{~s}$ and no count and Turkey's small vehicle-w/CS and small vehicle-w/o CS. Comparing results between the two countries, the average startup time in Turkey is shorter than the value from Japan's experiment. The reasons are possibly from, first, the limitation from experiment itself and, second, the cycle length and red time preset in Japan's experiment rather short. However, based on the results from both countries, it can be concluded that startup delay can be shortened by approximately 1 second by countdown signal. Also, this benefit can be seen clearly even until the third vehicle. Therefore, the installation of countdown signal can increase the capacity of intersection, especially to large vehicles where a large amount of delay can be shortened.

4.2. Premature Start. It is clear that countdown signal induces the increases in premature start. However, in the real implementation in Turkey, with the installation of CCTV together can reduce premature start by almost 100\% (see Figure 8 for the value between -1 and 0 on $x$-axis), and pedestrians cause drivers to be more careful (see Table 9). 
TABLE 10: Average startup delay in both countries.

\begin{tabular}{ccccc}
\hline \multicolumn{2}{c}{ Country/signal displayed } & First car & Second car & Third car \\
\hline \multirow{4}{*}{ Japan } & No count & 2.97 & 6.74 & 10.33 \\
& Count $1 \mathrm{~s} / 2 \mathrm{~s}$ & 1.95 & 5.50 & 8.51 \\
& Count $3 \mathrm{~s} / 4 \mathrm{~s}$ & 2.05 & 6.07 & 9.23 \\
& Count $5 \mathrm{~s} / 6 \mathrm{~s}$ & 1.97 & 5.89 & 9.35 \\
\hline \multirow{4}{*}{ Turkey } & Small vehicle-w/o CS & 1.23 & 4.61 & 6.76 \\
& Small vehicle-w/CS & 0.32 & 3.48 & 5.57 \\
& Large vehicle-w/o CS & 1.70 & 5.24 & 7.76 \\
& Large vehicle-w/CS & 0.76 & 4.04 & 6.49 \\
\hline
\end{tabular}

Furthermore, the distance from vehicle to stop line is also a very important factor to control premature start. It is possible to locate the stop line a little far from the intersection in order that if the premature start occurred, it will not conflict with pedestrians.

However, if the stop line is located too far, it is also possible that drivers will violate the stop line. Therefore, it is necessary to pay more attention in this issue in the real implementation. In addition, in order to control premature start, we tested several methods to display countdown number as the number disappeared a little while (from 1 to 6 seconds in our experiment) before the signal actually changes from red to green. Based on the results in Table 5, to stop displaying the countdown number around 5-6 seconds before the signal changes can reduce premature start. Therefore, this kind of setting is considered as a method to control premature start. In addition, in Turkey, as yellow light is displayed before the signal changes from red and green, it is considered to be an important factor to induce premature start.

\section{Conclusion}

In this paper, we have analyzed the behavior of drivers toward the countdown signal during waiting at red light based on both Japan's experiment and a field survey on the real implementation at Kayseri, Turkey. The analysis results can be summarized as follows.

(1) Based on Japan's experiment, if the signal displays countdown number until about 1-2 seconds before the signal changes, the rate of premature start is rather high. On the other hand, if to stop displaying the number earlier, the startup delay becomes longer but the rate of premature start can be reduced.

(2) Based on the survey in Turkey, we can obtain several factors influence on startup delay. The countdown system can shorten startup delay, especially for large vehicles where their startup delay is originally quite long. Regarding premature start, the rate of premature start is rather high if there is no CCTV installed together with the countdown signal. In addition, the benefit from reduction of startup delay can be obtained even until the third vehicle in the queue.

(3) Based on the questionnaire on drivers' opinion in both countries, countdown signal can reduce stress

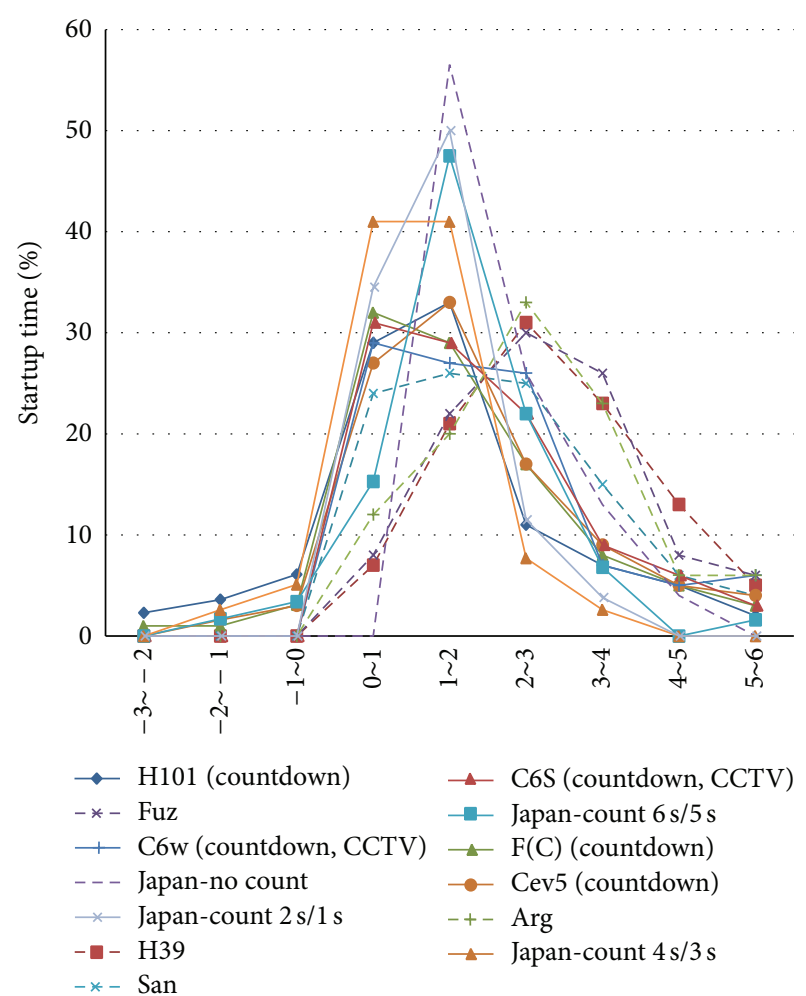

FIGURE 8: Distribution of startup delay comparing between Japan and Turkey.

during waiting at the red light. However, more indepth analysis on the relationship between countdown method and drivers' behaviors should be examined. Also, to improve validity of the results by increasing number of cases is important. In addition, there are many other impacts of countdown signal on drivers rather than ones presented here, such as the impacts of the countdown signal on drivers to decide whether to stop or to pass through intersection when signal changes from green to red. These issues remained for the future researches.

These findings can be of benefit for researchers and policy makers as they can be a guideline when to implement or to modify countdown-signalized intersections in many countries in order to increase safety of both drivers and pedestrians as well as drivers' satisfactions.

\section{Conflict of Interests}

The authors declare that there is no conflict of interests regarding the publication of this paper.

\section{References}

[1] K. M. Lum and H. Halim, "A before-and-after study on green signal countdown device installation," Transportation Research Part F: Traffic Psychology and Behaviour, vol. 9, no. 1, pp. 29-41, 2006. 
[2] S. C. Wong, N. N. Sze, and Y. C. Li, "Contributory factors to traffic crashes at signalized intersections in Hong Kong," Accident Analysis and Prevention, vol. 39, no. 6, pp. 1107-1113, 2007.

[3] M. R. Ibrahim, M. R. Karim, and F. A. Kidwai, "The effect of digital count-down display on signalized junction performance," American Journal of Applied Sciences, vol. 5, no. 5, pp. 479-482, 2008.

[4] F. A. Kidwai, M. R. Ibrahim, and M. R. Karim, "Traffic flow analysis of digital count down signalized urbanintersection," Journal of Proceedings of the Eastern Asia Society for Transportation Studies, vol. 5, pp. 1301-1308, 2005.

[5] S.-H. Chang, C.-Y. Lin, C.-C. Hsu, C.-P. Fung, and J.-R. Hwang, "The effect of a collision warning system on the driving performance of young drivers at intersections," Transportation Research Part F: Traffic Psychology and Behaviour, vol. 12, no. 5, pp. 371-380, 2009.

[6] G. Abe and J. Richardson, "The influence of alarm timing on braking in 10w speed driving," Safety Science, vol. 43, pp. 639654, 2005.

[7] S. Atev, O. Masoud, R. Janardan, and N. Papanikolopoulos, "Real time collision warning and avoidance at intersections," Tech. Rep. Mn/DOT 2004.45, 2004.

[8] BCAA Traffic Safety Foundation: British Columbia, Teenagers and Crashes, BCAA, 2008.

[9] Buckinghamshire County Council, Younger Drivers-Some Factors 2007, BCC, 2008.

[10] W. H. Chen, C. Y. Lin, and J. L. Doong, "Effects of interface workload of In.vehicle information systems on driving safety," Transportation Research Record, no. 1, pp. 73-78, 2005.

[11] S. B. Huey and D. Ragland, "Changes in driver behavior resulting from pedestrian countdown signals," in Proceedings of the Annual Meeting Transportation Research Record, November 2006.

[12] M. R. Ibrahim, M. R. Karim, and F. A. Kidwai, "The effect of digitalcount-down display on signalized junction performance," American Journal of Applied Science, vol. 5, no. 5, pp. 479-482, 2008.

[13] J. Joseph and G.-L. Chang, "Saturation flow rates and maximum critical lane volumes for planning applications in Maryland," Journal of Transportation Engineering, vol. 131, no. 12, pp. 946952, 2005.

[14] T. Yoda and A. Mitsuboshi, "A study on the effects of countdown signal on pedestrians," in Proceeding of the Annual Meeting of JSCE-Kansai, pp. IV-47.1-IV-47.2, 2001, (Japanese).

[15] M. Fujita, K. Suzuki, and C. Yilmaz, "Behavior and consciousness analyses of effect of traffic signals including countdown device for vehicles," Journal of the Eastern Asia Society for Transportation Studies, vol. 7, pp. 2289-2304, 2007.

[16] M. Fujita, K. Suzuki, and C. Yilmaz, "Analysis of the effects of countdown signals to drivers in Kayseri Province, Turkey," in Proceedings of the 7th ITS Symposium, vol. 7, pp. 169-174, 2008, (Japanese).

[17] H. Hamaoka, M. Suzuki, and Y. Nakamura, "Safety assessment of acquiring the traffic signal information by driver behavior," Infrastructure Planning Review, vol. 25, no. 4, pp. 919-928, 2006 (Japanese).

[18] M. Fujita, K. Yu, K. Suzuki, and C. Yilmaz, "Study on behavior of vehicles starts under countdown-type traffic signal through test run in Japan and survey in Turkey," Journal of Japan Society of Civil Engineers, Series D3, vol. 67, no. 5, pp. 181-191, 2011 (Japanese).
[19] Kasetsart University, The Development, The Administration and the Management of Intelligent Transportation System: A Review Report, Officeof Traffic and Transport Planning and Policy, Bangkok, Thailand, 2004.

[20] O. Keegan and M. O’Mahony, "Modifying pedestrian behavior," Transportation Research Part A, vol. 37, pp. 889-901, 2003.

[21] F. A. Kidwai, M. R. Karim, and M. R. Ibrahim, "Traffic flow analysis of digital count down signalized urban intersection," Journal of the Eastern Asia Society for Transportation Studies, vol. 5, pp. 1301-1308, 2005.

[22] K. W. Kim, Y. Kim, and H. Y. Seo, "An evaluation of pedestrian countdown signals," KSCE Journal of Civil Engineering, vol. 6, no. 4, pp. 533-537, 2002.

[23] H. Koll, M. Bader, and K. W. Axhausen, "Driver behavior during flashing green before amber: a comparative study," Accident Analysis \& Prevention, vol. 36, pp. 273-280, 2004.

[24] D. Mahalel, D. Zaidel, and T. Klein, "Driver's decision process on termination of the green light," Accident Analysis \& Prevention, vol. 17, no. 5, pp. 373-380, 1985.

[25] R. N. Mussa, C. J. Newton, J. S. Matthias, E. K. Sadalla, and E. K. Burns, "Simulator evaluation of green and flashing amber signal phasing," Transportation Research Record, vol. 1550, pp. 23-29, 1996. 


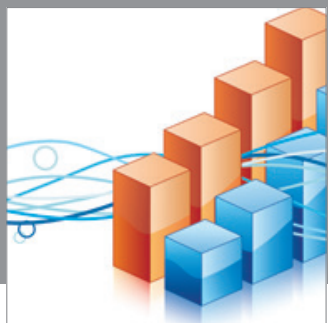

Advances in

Operations Research

mansans

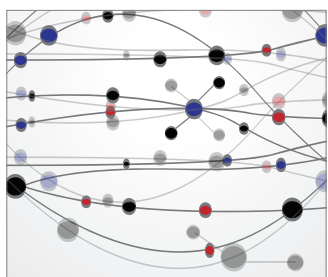

The Scientific World Journal
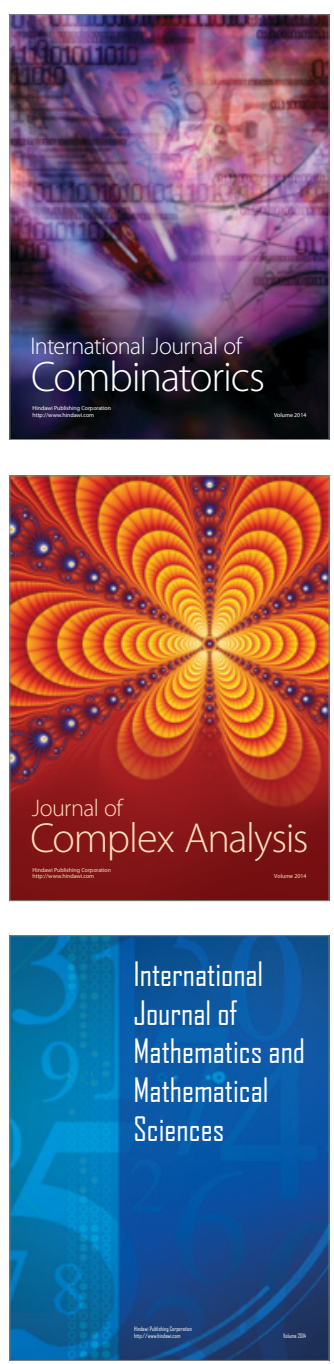
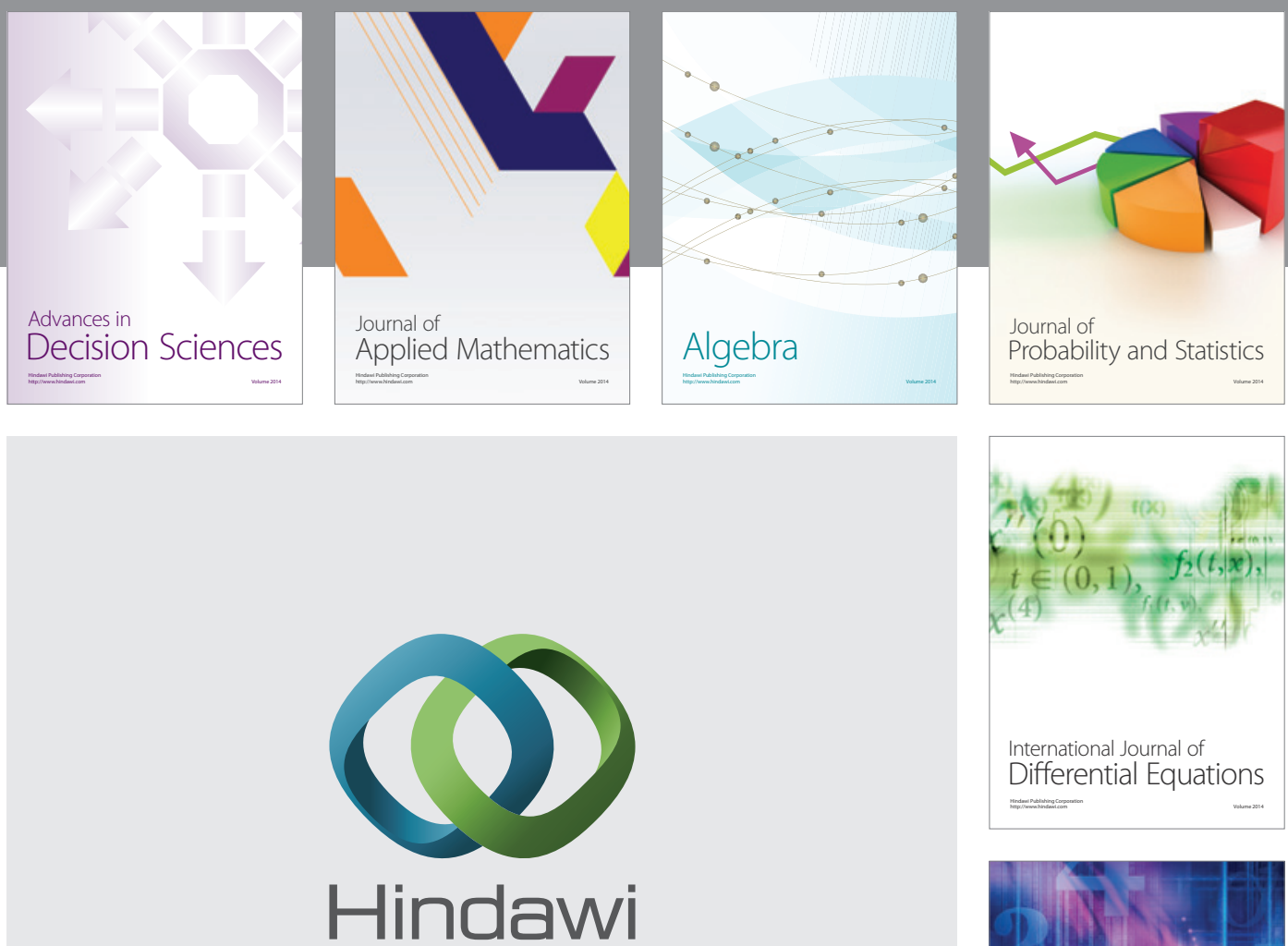

Submit your manuscripts at http://www.hindawi.com
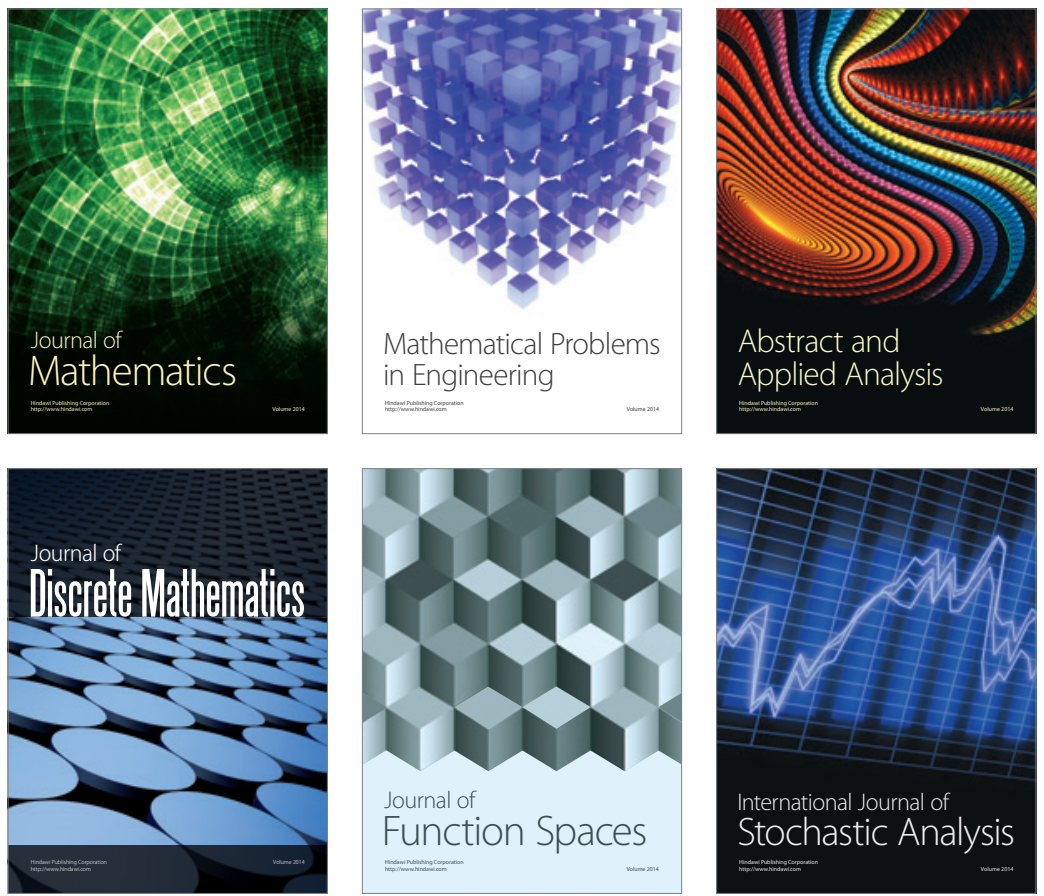

Journal of

Function Spaces

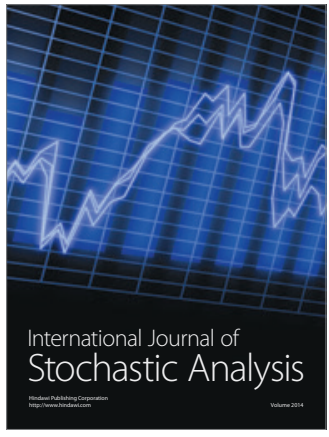

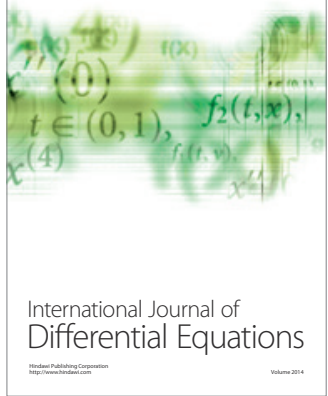
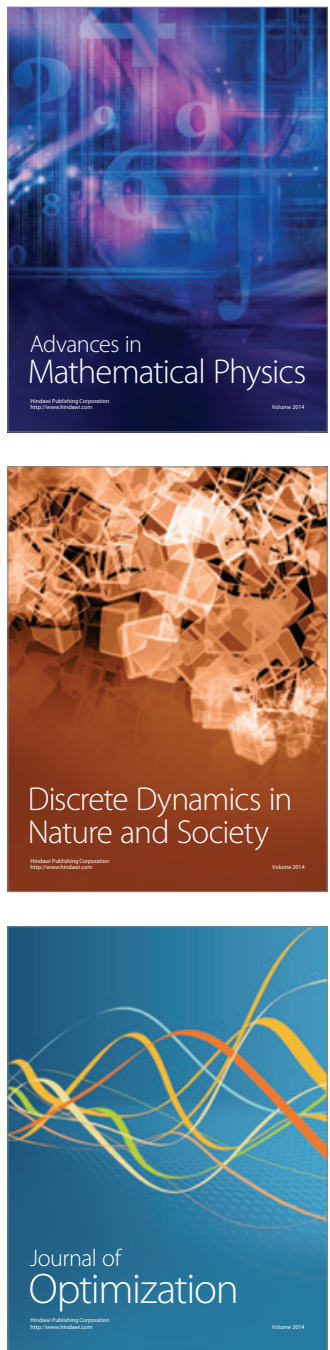